\title{
Efeito da ractopamina e do gênero no desempenho e na carcaça de suínos de diferentes genótipos halotano
}

\author{
Effects of ractopamine and gender on performance and carcass \\ quality of swine with different halothane genotypes
}

\author{
Ana Maria Bridi ${ }^{1 *}$; Audiléia Rocha de Oliveira ${ }^{2}$; Nilva Aparecida da Fonseca ${ }^{1}$; \\ Luiz Lehmann Coutinho ${ }^{3}$; Edgar Hideaki Hoshi"; \\ Julian Cristina Borosky"; Caio Abércio da Silva ${ }^{1}$
}

Resumo

Com o objetivo de avaliar o efeito da ractopamina sobre o desempenho e a qualidade da carcaça de suínos dos genótipos halotano homozigoto dominante e heterozigoto, 24 machos castrados e 12 fêmeas, sendo metade de cada genótipo, foram submetidos aos tratamentos. O delineamento experimental utilizado foi em blocos casualizados em arranjo fatorial $2 \times 2 \times 2$, sendo dois genótipos halotano (homozigoto dominante e heterozigoto), duas rações (controle sem adição de ractopamina e com 10 ppm de ractopamina) e dois gênero (machos castrados e fêmeas). Avaliou-se o desempenho, a carcaça e a viabilidade econômica do uso da ractopamina. Todas as interações binárias avaliadas não foram significativas como também não houve diferença entre genótipos homozigoto dominante e heterozigotos para as características de desempenho e de qualidade da carcaça, exceto para a variável consumo de ração $(\mathrm{P}<0,05)$, onde os suínos heterozigotos consumiram mais ração. Não foram observados efeitos para o fator ractopamina para todas as variáveis avaliadas. Conclui que o desempenho e as características de carcaça suína não foram afetados pelo genótipo halotano e pela adição de ractopamina na ração.

Palavras-chave: $\beta$-adrenérgico, gene rianodina, análise econômica

\begin{abstract}
The objective of this experiment was to evaluate the ractopamine effect on performance and carcass quality of swine carriers of the dominant homozygote and heterozygote halothane genotypes. It were used 24 barrows and 12 gilts, half of each genotype. The experimental design used was a randomized block under a $2 \times 2 \times 2$ factorial arrangement comprising two halothane genotypes (dominant homozygote and heterozygote), two rations (one containing $10 \mathrm{ppm}$ of ractopamine and another without ractopamine) and two genders (barrows and gilts). It were evaluated the performance, carcass and the economic viability of the ractopamine use. All the binary interactions evaluated were not significant as there was no difference among the dominant homozygote and heterozygote genotypes on the performance and carcass quality characteristics, except to the variable ration consumption $(\mathrm{P}<0.05)$, where the heterozygote swine consumed more. As a result of this experiment it was found that the performance and the carcass characteristics of the swine were not affected by the presence of the halothane genotypes and by the addition of ractopamine to the ration.
\end{abstract}

Key words: Beta-adrenergic, ryanodine receptor gene, economic analyse

Professor Doutor do Departamento de Zootecnia da UEL. Londrina, PR. (ambridi@uel.br; casilva@uel.br; nilva@uel.br).

Aluno do Programa de Pós-Graduação em Ciência dos Alimentos. Londrina, PR.

Professor Doutor do Departamento de Produção Animal da ESALQ. Piracicaba, SP

4 Aluno do Programa de Pós-Graduação em Ciência Animal. Londrina, PR

Autor para correspondência 


\section{Introdução}

Uma das estratégias adotadas visando aumentar a eficiência da produção e melhorar a qualidade da carne, incrementando a deposição de músculo na carcaça em detrimento da gordura foi o uso de genótipos especializados na produção de carne, que resultou no aumento da freqüência do gene halotano nas linhagens terminais. O gene halotano, também conhecido como gene rianodina, é de interesse comercial porque pode promover um aumento de 2 a 4 pontos percentuais de carne na carcaça, entretanto, resulta em um produto de qualidade inferior, principalmente no que se refere a incidência de PSE (carne de textura mole, de cor pálida e que retém pouca água), que é indesejável tanto para o consumo "in natura" como para o processamento industrial (SATHER et al., 1991; CHANNON; PAYNE; WARNER, 2000; FISHER; MELLETT; HOFFMAN, 2000; HAMILTON et al., 2000; BRIDI et al., 2003).

Fujii et al. (1991) identificaram uma mutação de ponto no gene que codifica a proteína rianodina (RYR1), que faz parte do canal de $\mathrm{Ca}^{2+}$ do retículo sarcoplasmático. A mutação ocorreu no cromossomo 6, onde uma base nitrogenada citosina sofre mutação para timina na posição 1843 da seqüência de DNA, resultando na alteração do aminoácido 615 , onde um resíduo de arginina cede lugar a um resíduo de cisteína, induzindo a hipersensibilidade do canal regulador de $\mathrm{Ca}^{2+}$, abrindo-o. Depois de aberto, o canal não responde a presença de $\mathrm{Ca}^{2+}$ e $\mathrm{Mg}^{2+}$, que conduzem ao seu fechamento, desta maneira a contratura muscular é ativada, levando ao hipermetabolismo e hipertermia.

Uma ação recente que vem sendo adotada, visando também aumentar a quantidade de carne na carcaça, é o uso dos promotores do crescimento com características químicas e atividades semelhantes aos hormônios denominados de catecolaminas. A ractopamina representa a principal substância com esta ação. Trata-se de um agonísta $\beta$-adrenérgico, repartidor de nutrientes, análogo estrutural da adrenalina e noradrenalina, que promove o crescimento e a deposição de tecido magro e a redução no teor de gordura na carcaça de suínos em terminação.

Os efeitos sobre o desempenho produtivo de suínos que receberam ractopamina na ração são inconsistentes. Os resultados da ação dependem dos níveis de substância utilizada, do tempo de fornecimento e de retirada do produto antes do abate, nos níveis de lisina na ração, da linhagem de suíno usada e da idade e peso nos animais ao início da suplementação (CUARON; MEJIAGUADARRAMA, 2002; POLICARPIO; CASTRO, 2002; SEE; ARMSTRONG; WELDON, 2002; ZAGURY et al., 2002). Bark, Stahly e Cromwell (1989) observaram que animais com maior capacidade genética para deposição de tecido magro apresentaram efeito da ractopamina mais acentuado.

Este trabalho teve como objetivo avaliar os efeitos e as possíveis interações da adição de ractopamina na ração de suínos do genótipo halotano homozigoto dominante $\left(\mathrm{Hal}^{\mathrm{NN}}\right)$ e heterozigoto $\left(\mathrm{Hal}^{\mathrm{Nn}}\right)$ sobre o desempenho e a qualidade da carcaça.

\section{Material e Métodos}

Para a identificação do gene halotano foi coletado $5 \mathrm{~mL}$ de sangue em tubos à vácuo com anti-coagulante ácido etilenodiaminotetracético (EDTAK3 a $15 \%$ - $54 \mu \mathrm{L} /$ tubo) de 200 suínos recém nascidos, da genética Agroceres - PIC, em uma granja multiplicadora de suínos, localizada na cidade de Londrina-PR.

A análise do DNA(ácido desoxirribonucléico) foi realizada no Laboratório de Biotecnologia Animal da ESALQ- Piracicaba, SP. O DNA genômico foi extraído adaptando-se o protocolo descrito por Miller, Dykes e Polesky (1988). Um fragmento da seqüência de DNA do gene do receptor rianodina suíno foi amplificado pela técnica de PCR (reação da polimerase em cadeia) segundo Fujii et al. (1991). 
O produto da amplificação por PCR foi clivado para a análise do polimorfismo do comprimento dos fragmentos de restrição (RLPC). Para verificação do polimorfismo do comprimento dos fragmentos de restrição, as amostras foram submetidas à eletroforese em gel de agarose. A digestão dos produtos de amplificação, com a enzima HhaI, permitiu observar dois fragmentos (de 49 e 32 pares de bases) para animais homozigotos normais $\left(\mathrm{Hal}^{\mathrm{NN}}\right.$ ), três fragmentos (de 49, 32 e 81 pares de bases) para heterozigotos $\left(\mathrm{Hal}^{\mathrm{Nn}}\right)$ e somente um fragmento (de 81 pares de bases) para indivíduos mutantes $\left(\mathrm{Hal}^{\mathrm{nn}}\right)$.

A partir destas análises foram selecionados 18 suínos homozigotos dominantes $\left(\mathrm{Hal}^{\mathrm{NN}}\right)$ e 18 heterozigotos $\left(\mathrm{Hal}^{\mathrm{Nn}}\right)$ para o gene halotano, sendo 6 fêmeas e 12 machos de cada genótipo. Os animais selecionados foram transferidos e criados no Setor de Suinocultura da Fazenda Escola da Universidade Estadual de Londrina até iniciar o experimento. $\mathrm{O}$ experimento teve início quando os suínos atingiram, em média, $72,7 \pm 5,5 \mathrm{~kg}$ de peso vivo e teve uma duração de 21 dias. A diferença observada no peso inicial entre machos e fêmeas é devido ao número limitado de animais geneticamente selecionados para ao gene halotano.

As rações foram fornecidas à vontade para as fases de crescimento II (início do experimento até $80 \mathrm{~kg}$ de peso vivo) e terminação ( $80 \mathrm{~kg}$ de peso vivo até o abate) e seguiram as recomendações mínimas do National Research Council - NRC (1998). A composição das rações pode ser visualizada na Tabela 1 .

Tabela 1. Composição e valor nutricional das rações consumidas nas fases de crescimento e terminação

\begin{tabular}{lcc}
\hline & Composição da ração & \\
\hline Ingrediente (\%) & Crescimento & Terminação \\
\hline Milho & 73,26 & 74,612 \\
Farelo de soja & 19,62 & 18,375 \\
Suplemento mineral e vitamínico* & 4,0 & 4,0 \\
Ractopamina ou material inerte & 0,050 & 0,050 \\
Óleo de soja & 2,53 & 2,476 \\
L-lisina HCl 78\% & 0,285 & 0,237 \\
Sal comum & 0,25 & 0,25 \\
\hline Valor nutricional & & \\
\hline Energia metabolizavel (Kcal/kg) & 3.265 & 3.265 \\
Proteína bruta (\%) & 15,5 & 15,0 \\
Fibra bruta (\%) & 2,7 & 2,649 \\
Matéria seca (\%) & 88,204 & 88,173 \\
Gordura (\%) & 5,196 & 5,178 \\
Fósforo total (\%) & 0,284 & 0,280 \\
Cálcio (\%) & 0,093 & 0,089 \\
Metionina (\%) & 0,252 & 0,246 \\
Lisina (\%) & 0,970 & 0,90 \\
\hline
\end{tabular}

* Suplemento mineral e vitamínico de crescimento - por quilograma do produto: Ácido fólico 28 mg; Ácido pantotênico 280 mg; Antioxidante 9mg; Biotina 1,5 mg; Cálcio 190 g; Cobalto 4,6 mg; Cobre3.412 mg; Colina 4 g; ferro2.900 mg; Flúor 595 mg; Fósforo62 g; Iodo 37 mg; Manganês 1.200 mg; Niacina554 mg; Piridoxina 50 mg; Promotor de crescimento 2.000 mg; Riboflavina $112 \mathrm{mg}$; Selênio $9 \mathrm{mg}$; Sódio $54 \mathrm{~g}$; Tiamina $28 \mathrm{mg}$; Vitamina A $140.000 \mathrm{UI} / \mathrm{kg}$; Vitamina B12 $700 \mathrm{mcg}$; Vitamina D3 56.000 UI/kg; Vitamina E $280 \mathrm{mg}$; Vitamina K3 56 mg; Zinco $2.750 \mathrm{mg}$.

Suplemento mineral e vitamínico de terminação - por quilograma do produto: Ácido fólico 8,8 mg; Ácido pantotênico $173 \mathrm{mg}$; Antioxidante $9 \mathrm{mg}$; Biotina 0,42 mg; Cálcio 190 g; Cobalto 3,6 mg; Cobre 2.126 mg; Ferro 1.820 mg; Flúor 485 mg; Fósforo 49 g; Iodo) 29,5 mg; Manganês 836 mg; Niacina 426 mg; Piridoxina 13,3 mg; Promotor de crescimento 1.485 mg; Riboflavina 71 mg; Selênio 8 mg; Sódio 58,5 g; Tiamina 13,3 mg; Vitamina A) 93.000 UI/kg; Vitamina B12 520 mcg; Vitamina D3 24.000 UI/kg; Vitamina E $106 \mathrm{mg}$; Vitamina K3 56 mg; Zinco $2.049 \mathrm{mg}$. 
Para avaliar o ganho de peso, os suínos foram pesados no início do experimento, ao final do período de crescimento e um dia antes do abate. Para estimar o consumo de ração, toda a ração fornecida aos animais foi pesada e o desperdício e as sobras de ração no comedouro foram descontadas do total administrado.

Ao atingirem o peso médio de 94,2 $\pm 6,9 \mathrm{~kg}$, os animais foram abatidos em um matadouro localizado a $30 \mathrm{Km}$ da Fazenda Escola. Retirou-se a ração 12 horas antes do transporte e os animais permaneceram em dieta hídrica até o abate. Os suínos foram embarcados às cinco horas da manhã. O tempo de transporte foi de aproximadamente uma hora. Os animais permaneceram nas baias de descanso no frigorífico por menos de uma hora. Os suínos foram insensibilizados via corrente elétrica, com um equipamento da marca Petrovina ${ }^{\circledR}$ IS 2000 com dois eletrodos, utilizando-se 350 volts e 1,3 ampères. $\mathrm{O}$ choque elétrico foi aplicado por um período de aproximadamente três (03) segundos. Os animais foram abatidos pelo corte da veia jugular. A sangria foi realizada com os animais na horizontal. Após o abate, escaldagem e evisceração, as carcaças foram divididas ao meio no sentido longitudinal. As carcaças foram resfriadas à temperatura $2 \pm 2^{\circ} \mathrm{C}$, por 24 horas, na câmara de resfriamento no frigorífico.

As carcaças foram pesadas logo após o abate (peso da carcaça quente) e 24 horas depois do resfriamento (peso da carcaça resfriada). O rendimento de carcaça foi calculado pela porcentagem do peso da carcaça quente em relação ao peso do suíno vivo.

As meias carcaças esquerdas foram seccionadas na altura da última costela para realização das medidas de área de olho de lombo segundo as normas da ASSOCIAÇÃO BRASILEIRA DE CRIADORES DE SUÍNOS (1973). A profundidade do músculo longissimus dorsi e a espessura de gordura foram medidas na altura da última costela, a $6 \mathrm{~cm}$ da linha média de corte. Para calcular o rendimento e a quantidade de carne na carcaça usaram-se as seguintes equações, conforme Guidoni (2000):
- Rendimento de carne $=65,92-$ (espessura de gordura $\mathrm{x} 0,685)+$ (profundidade do músculo $\mathrm{x}$ $0,094)+(0,026 \times$ peso de carcaça quente $)$

- Quantidade de carne na carcaça =7,38-(espessura de gordura x 0,487$)+$ (profundidade do músculo x 0,059$)+($ peso de carcaça quente x 0,525$)$

O estudo da viabilidade econômica do uso da ractopamina em diferentes genótipos halotano foi realizado pela determinação do custo médio em ração por quilograma de peso vivo (Yi) durante o período experimental, conforme Bellaver et al. (1985). Os índices de eficiência econômica (IEE) e de custo médio (IC) foram calculados segundo Barbosa et al. (1992) conforme as equações descritas a seguir:

$$
\begin{gathered}
\text { IEE }=\text { Mce } / \text { Ctei x } 100 \\
\text { IC }=\text { Ctei } / \text { Mce } \times 100
\end{gathered}
$$

Onde: Mce $=$ menor custo médio em ração por quilograma de peso vivo ganho, observado entre os tratamentos; Ctei $=$ custo médio do tratamento considerado.

Os preços dos ingredientes utilizados na elaboração dos custos da ração foram obtidos na região de Londrina no mês de junho de 2004, sendo: farelo de soja ( $\mathrm{R} \$ 1,02 / \mathrm{kg})$, L-lisina ( $\mathrm{R} \$ 19,00 /$ $\mathrm{kg})$, milho grão $(\mathrm{R} \$ 0,54 / \mathrm{kg})$, núcleo crescimento ( $\mathrm{R} \$ 1,27 / \mathrm{kg})$, núcleo terminação ( $\mathrm{R} \$ 1,07 / \mathrm{kg})$, óleo vegetal $(\mathrm{R} \$ 2,5 / \mathrm{kg})$, ractopamina $(\mathrm{R} \$ 140,00 / \mathrm{kg})$ e sal $(\mathrm{R} \$ 0,95 / \mathrm{kg})$.

O delineamento experimental utilizado foi em blocos casualizados em arranjo fatorial $2 \times 2 \times 2$, dois genótipos halotano (homozigoto dominante e heterozigoto), duas rações (grupo controle, sem adição de ractopamina e tratados com 10 ppm de ractopamina) e dois sexos (machos castrados e fêmeas). Os animais foram blocados em função do seu peso inicial. A unidade experimental foi constituída de uma baia. Foram utilizadas 24 baias, doze com uma fêmea por baia e doze com dois machos castrados por baia. 
Estimativas de consumo médio de ração e de conversão alimentar foram obtidas usando as informações coletadas por baia. A análise da variância foi realizada pelo programa estatístico SAEG, versão 7.1 (UNIVERSIDADE FEDERAL DE VIÇOSA, 1997). Para análise da variância dos dados de desempenho usou-se o peso inicial como covariável e para os dados de carcaça usou-se como covariável o peso vivo final.

\section{Resultados e Discussão}

Os resultados da análise do desempenho dos suínos em relação ao genótipo e ao uso de ractopamina e gênero encontram-se na Tabela 2.

Tabela 2. Médias e desvios padrões de peso inicial, peso final, ganho diário de peso, consumo diário de ração e conversão alimentar de acordo com o genótipo, ractopamina e sexo

\begin{tabular}{lccccc}
\hline & Peso inicial, kg & Peso final, kg & $\begin{array}{c}\text { Consumo diário } \\
\text { de ração, kg }\end{array}$ & $\begin{array}{c}\text { Ganho diário de } \\
\text { peso, kg }\end{array}$ & $\begin{array}{c}\text { Conversão } \\
\text { alimentar }\end{array}$ \\
\hline Genótipo & & & & & \\
Hal $^{\mathrm{NN}}$ & $72,20 \pm 5,27$ & $93,02 \pm 5,96$ & $2,87 \pm 0,24 \mathrm{~b}$ & $1,00 \pm 0,10$ & $2,87 \pm 0,27$ \\
Hal $^{\mathrm{Nn}}$ & $73,26 \pm 5,80$ & $94,53 \pm 7,72$ & $3,00 \pm 0,25 \mathrm{a}$ & $1,03 \pm 0,14$ & $2,54 \pm 0,29$ \\
\hline Ractopamina & & & & & \\
Sem & $72,69 \pm 4,67$ & $93,86 \pm 5,32$ & $2,91 \pm 0,26$ & $1,03 \pm 0,08$ & $3,03 \pm 0,27$ \\
Com 10 ppm & $72,58 \pm 6,38$ & $93,67 \pm 8,28$ & $2,91 \pm 0,24$ & $1,00 \pm 0,15$ & $3,19 \pm 0,29$ \\
\hline Gênero & & & & & \\
Macho castrado & $74,73 \pm 5,89 \mathrm{a}$ & $97,05 \pm 6,67$ & $3,11 \pm 0,27 \mathrm{a}$ & $1,09 \pm 0,10$ & $2,88 \pm 0,28$ \\
Fêmea & $70,53 \pm 4,21 \mathrm{~b}$ & $90,48 \pm 5,81$ & $2,76 \pm 0,31 \mathrm{~b}$ & $0,95 \pm 0,13$ & $2,94 \pm 0,30$ \\
\hline Coeficiente de variação & 3,15 & 2,56 & 5,39 & 11,27 & 8,98 \\
\hline
\end{tabular}

a,b Médias seguidas de letras diferentes na mesma coluna diferem pelo teste $\mathrm{F}(\mathrm{P}<0,05)$

A análise de variância indicou não haver $(\mathrm{P}<0,05)$ nenhuma interação binária entre as variáveis avaliadas. Stoller et al. (2003) também não verificaram interação da suplementação dietética de ractopamina com linhagem genética de suínos, concluindo que o efeito da administração de ractopamina na dieta independe da base genética. Ao estudar a interação entre genótipo halotano e somatotropina porcina, Dugan et al. (1997) também não verificaram efeito significativo para as características de desempenho.

Não houve diferença entre os suínos normais $\left(\mathrm{Hal}^{\mathrm{NN}}\right)$ e os portadores do gene halotano $\left(\mathrm{Hal}^{\mathrm{Nn}}\right)$ para as características de desempenho, exceto para a variável consumo de ração, onde os suínos heterozigotos consumiram mais ração que os homozigotos dominantes. Ao comparar suínos $\mathrm{Hal}^{\mathrm{Nn}}$ com Hal ${ }^{\mathrm{NN}}$, Sather et al. (1991); Leach et al. (1996) e Bridi et al. (2003) também não encontraram diferenças no ganho de peso diário durante o período de terminação. Entretanto, Leach et al. (1996) verificaram que a conversão alimentar foi melhor para os animais heterozigotos devido a maior deposição de carne na carcaça em relação aos suínos livres do gene halotano.

No presente estudo, o uso de $10 \mathrm{ppm}$ de ractopamina na ração não afetou o consumo diário de ração, o ganho de peso diário, o peso final e a conversão alimentar dos suínos. $\mathrm{Na}$ literatura, os resultados da ação da ractopamina sobre o desempenho são variados e dependem da concentração da droga na ração, do tempo de fornecimento e de retirada do produto antes do abate e da linhagem de suínos utilizada. Segundo See, Armstrong e Weldon (2002), suínos que tiveram a adição de 5 e 10 ppm de ractopamina na 
ração apresentaram melhor ganho de peso diário e uma melhor conversão alimentar, em comparação ao grupo controle. Resultados semelhantes foram observados por Cuaron e Mejia-Guadarrama (2002) e Policarpio e Castro (2002), para concentrações de 5 e 10; 20 ppm e 5 e 10 ppm de ractopamina, respectivamente.

Para que a ractopamina possa otimizar o crescimento, os parâmetros de carcaça e a síntese protéica no tecido muscular, é necessário fornecer níveis de proteína e de aminoácidos, principalmente de lisina, na ração acima dos valores convencionalmente utilizados nas dietas. Anderson et al. (2002) e Armstrong, Kremer e Spike. (2002) recomendam que em dietas contendo ractopamina os níveis de proteína bruta devem ser superiores a $16 \%$ e de lisina superiores a $1,0 \%$ e que os demais aminoácidos devem ser acrescidos em proporções relativas à lisina. No presente trabalho, utilizouse valores de proteína bruta de 15,50 e $15 \%$ e de lisina de 0,97 e 0,90\% nas rações de crescimento e terminação, respectivamente, fato que pode ter resultado na falta de resposta dos animais que usaram ractopamina.
Reeds (1991) apud Mersmann (1995) explica que uma das ações específicas dos agentes $\beta$-adrenérgicos pode ser a alteração do perfil de aminoácidos que são depositados na massa muscular. Isso implica na dedução de que alterações no fornecimento de aminoácidos limitantes, conseqüentemente, poderiam alterar a eficiência do uso das fontes de proteína, sendo estas capazes de suportar a demanda para a deposição de compostos protéicos estimulada pelos agentes promotores de crescimento.

Não houve diferença $(\mathrm{P}>0,05)$ entre os gêneros em relação às características de desempenho, exceto para consumo diário de ração, onde os machos castrados apresentaram $(\mathrm{P}<0,05)$ maior consumo em relação as fêmeas. Os machos castrados consumiram 350 gramas a mais de ração por dia que as fêmeas.

Os valores médios dos dados referentes ao peso de carcaça quente e resfriada, rendimento de carcaça e perda de peso no resfriamento em relação ao genótipo halotano, ractopamina e gênero encontram-se na Tabela 3.

Tabela 3. Médias e desvios padrões de peso de carcaça quente, rendimento de carcaça, peso de carcaça resfriada e perda de peso de carcaça no resfriamento de acordo com o genótipo, a ractopamina e sexo

\begin{tabular}{lcccc}
\hline & $\begin{array}{c}\text { Peso de carcaça } \\
\text { quente, } \mathrm{kg}\end{array}$ & $\begin{array}{c}\text { Rendimento de } \\
\text { carcaça, \% }\end{array}$ & $\begin{array}{c}\text { Peso carcaça } \\
\text { resfriada, kg }\end{array}$ & $\begin{array}{c}\text { Perda de peso } \\
\text { resfriamento, \% }\end{array}$ \\
\hline Genótipo & $71,76 \pm 5,69$ & $76,58 \pm 2,04$ & $70,28 \pm 5,36$ & $2,04 \pm 0,89$ \\
Hal $^{\mathrm{NN}}$ & $73,26 \pm 5,95$ & $76,17 \pm 1,61$ & $71,63 \pm 5,57$ & $2,18 \pm 0,80$ \\
Hal $^{\mathrm{Nn}}$ & & & & \\
\hline Ractopamina & $72,75 \pm 4,11$ & $76,51 \pm 1,52$ & $71,22 \pm 3,91$ & $2,09 \pm 0,80$ \\
Sem & $72,27 \pm 7,19$ & $76,23 \pm 1,23$ & $70,69 \pm 6,72$ & $2,13 \pm 0,90$ \\
Com 10 ppm & & & \\
Gênero & $74,61 \pm 4,80 \mathrm{a}$ & $76,68 \pm 1,70$ & $72,67 \pm 4,62$ & $2,60 \pm 0,55 \mathrm{a}$ \\
Macho castrado & $68,65 \pm 5,58 \mathrm{~b}$ & $75,81 \pm 1,98$ & $67,82 \pm 5,55$ & $1,22 \pm 0,41 \mathrm{~b}$ \\
Fêmea & 4,53 & 2,39 & 4,55 & 26,87 \\
\hline Coeficiente de variação & & &
\end{tabular}

${ }^{\mathrm{a}, \mathrm{b}}$ Médias seguidas de letras diferentes na mesma coluna diferem pelo teste $\mathrm{F}(\mathrm{P}<0,05)$ 
Suínos homozigotos dominantes e heterozigotos não apresentaram diferenças $(\mathrm{P}>0,05)$ para os valores médios de peso de carcaça quente, rendimento de carcaça, peso de carcaça resfriada e perda de peso de carcaça durante o resfriamento. Resultados semelhantes foram verificados por Bridi et al. (2003). Porém, Jones et al. (1988) constataram que carcaças de suínos $\mathrm{Hal}^{\mathrm{Nn}}$ perderam de 1 a $3 \%$ mais peso durante o resfriamento da carcaça que os suínos $\mathrm{Hal}^{\mathrm{NN}}$.

A análise do peso da carcaça quente, rendimento de carcaça, peso de carcaça resfriada e perda de peso de carcaça durante o resfriamento não mostrou diferença $(\mathrm{P}>0,05)$ entre os suínos suplementados ou não com ractopamina.

Os suínos machos castrados, comparados com as fêmeas, apresentaram $(\mathrm{P}>0,05)$, em média, $5,9 \mathrm{~kg}$ a mais de peso de carcaça quente e tiveram $1,4 \%$ a mais de perda de peso de carcaça durante o resfriamento.

A Tabela 4 apresenta os dados médios do efeito do genótipo halotano, da ractopamina e do gênero no comprimento de carcaça, área de olho de lombo, profundidade do músculo, espessura de gordura, rendimento de carne magra e quantidade de carne na carcaça.

Tabela 4. Médias e desvios padrões do efeito do genótipo, da ractopamina e do sexo nas características quantitativas da carcaça de suínos

\begin{tabular}{lcccccc}
\hline & $\begin{array}{c}\text { Comprimento } \\
\text { de carcaça, cm }\end{array}$ & $\begin{array}{c}\text { Área olho } \\
\text { lombo, } \mathrm{cm}^{2}\end{array}$ & $\begin{array}{c}\text { Profundidade } \\
\text { músculo, mm }\end{array}$ & $\begin{array}{c}\text { Espessura } \\
\text { gordura, mm }\end{array}$ & $\begin{array}{c}\text { Rendimento } \\
\text { carne magra, \% }\end{array}$ & $\begin{array}{c}\text { Quantidade } \\
\text { carne carcaça, } \\
\mathrm{kg}\end{array}$ \\
\hline $\begin{array}{l}\text { Genótipo } \\
\mathrm{Hal}^{\mathrm{NN}}\end{array}$ & $91,48 \pm 3,32$ & $38,70 \pm 4,99$ & $56,48 \pm 6,07$ & $13,87 \pm 2,44$ & $59,86 \pm 1,64$ & $41,63 \pm 3,02$ \\
Hal $^{\mathrm{Nn}}$ & $91,65 \pm 3,26$ & $38,18 \pm 4,05$ & $58,15 \pm 4,44$ & $14,93 \pm 3,92$ & $59,25 \pm 2,55$ & $41,10 \pm 3,10$ \\
\hline Ractopamina & $93,04 \mathrm{a} \pm 2,77$ & $37,59 \pm 4,03$ & $57,45 \pm 3,35$ & $14,70 \pm 3,35$ & $59,35 \pm 2,11$ & $41,80 \pm 2,83$ \\
Sem & $90,08 \mathrm{~b} \pm 3,06$ & $39,29 \pm 3,95$ & $57,19 \pm 3,24$ & $14,10 \pm 3,24$ & $59,76 \pm 2,20$ & $41,83 \pm 3,29$ \\
Com 10 ppm & & & & & & \\
\hline Sexo & $91,46 \pm 3,70$ & $39,32 \pm 4,03$ & $58,04 \pm 5,27$ & $15,44 \pm 3,01 \mathrm{a}$ & $58,86 \pm 1,94 \mathrm{~b}$ & $42,36 \pm 2,90$ \\
Macho castrado & $91,75 \pm 2,30$ & $36,83 \pm 3,95$ & $55,98 \pm 5,34$ & $12,49 \pm 2,91 \mathrm{~b}$ & $60,84 \pm 1,91 \mathrm{a}$ & $40,64 \pm 2,99$ \\
Fêmea & 2,77 & 11,17 & 9,22 & 20,70 & 2,79 & 6,43 \\
\hline $\begin{array}{l}\text { Coeficiente de } \\
\text { variação }\end{array}$ & & & & & & \\
\hline
\end{tabular}

${ }^{\mathrm{a}, \mathrm{b}}$ Médias seguidas de letras diferentes na mesma coluna diferem pelo teste $\mathrm{F}(\mathrm{P}<0,05)$

A presença do gene halotano não afetou $(\mathrm{P}>0,05)$ as características quantitativas da carcaça de suínos. Suínos homozigotos dominantes e heterozigotos para o gene halotano apresentaram médias semelhantes de comprimento de carcaça, área de olho de lombo, profundidade do músculo longissimus dorsi, espessura de gordura, rendimento de carne na carcaça e quantidade de carne na carcaça. Os resultados concordam com aqueles obtidos por Sather et al. (1991). Entretanto, Bridi et al. (2003) verificaram que suínos portadores do gene halotano
$\left(\mathrm{Hal}^{\mathrm{Nn}}\right)$ apresentaram em média $6,3 \mathrm{~mm}$ a mais de profundidade de músculo lombar e $1 \mathrm{~mm}$ a menos de espessura de gordura, o que resultou em 1,6\% a mais de carne magra na carcaça em relação aos suínos livres do gene $\left(\mathrm{Hal}^{\mathrm{NN}}\right)$. Diferenças nas características quantitativas da carcaça entre genótipos halotano foram observadas também por Jones et al. (1988).

Suínos não tratados com ractopamina apresentaram maior comprimento de carcaça. Não houve diferença $(\mathrm{P}>0,05)$ entre os suínos 
suplementados ou não com ractopamina para as características deárea de olhodelombo, profundidade do músculo longissimus dorsi, espessura de gordura, rendimento de carne na carcaça e quantidade de carne na carcaça, discordando dos resultados observados por Cuaron e Mejia-Guadarrama (2002); Policarpio e Castro (2002); See, Armstrong e Weldon (2002) e Zagury et al. (2002), que verificaram que o tratamento com ractopamina promoveu um aumento no rendimento e deposição de tecido muscular nas carcaças e redução no teor de gordura. O aumento no conteúdo de carne na carcaça encontrado por Crenshaw et al. (1987) foi de 3,4\% e a redução na espessura de gordura foi de 3,0\%. Warris et al. (1990) observaram um acréscimo de 0,9\% no conteúdo de carne na carcaça e uma redução no teor de gordura de $0,8 \%$.

O efeito da ractopamina sobre o tecido muscular é mais pronunciado com o aumento da idade dos suínos, quando a deposição de tecido adiposo começa a superar a deposição de proteína. Os animais fisiologicamente imaturos possuem baixa densidade de receptores $\beta$-adrenérgicos ou pouca diferenciação dos receptores de ambos os tecidos, esquelético e adiposo (VERNON, 1986). A pouca idade, aproximadamente 140 dias, e o baixo peso de abate (média de $94 \mathrm{~kg}$ ) dos suínos do presente trabalho podem ter sido os responsáveis pela falta de resposta no desempenho e nas proporções de carne e gordura da carcaça para os animais suplementados com ractopamina.

Suínos machos castrados e fêmeas apresentaram ( $\mathrm{P}>0,05)$ valores semelhantes de comprimento de carcaça, área de olho de lombo, profundidade do músculo e quantidade de carne magra na carcaça. Os suínos machos castrados apresentaram maior espessura de gordura que as fêmeas e menor rendimento de carne magra na carcaça $(\mathrm{P}<0,05)$. Estes dados estão de acordo com a literatura que afirma que as fêmeas produzem carcaças de qualidade superiores a dos machos castrados para a mesma idade de abate (SATHER et al., 1991; LEACH et al., 1996).

$\mathrm{Na}$ Tabela 5 são apresentados os resultados do estudo da viabilidade econômica do uso da ractopamina nos genótipos halotano homozigoto dominante e heterozigoto.

Tabela 5. Custo médio de ração por quilograma ganho de peso vivo, índice de eficiência econômica e de custo para os genótipos halotano homozigoto dominante $\left(\mathrm{Hal}^{\mathrm{NN}}\right)$ e heterozigoto $\left(\mathrm{Hal}^{\mathrm{Nn}}\right)$ com $(\mathrm{CR})$ ou sem $(\mathrm{SR})$ adição de ractopamina na ração.

\begin{tabular}{lcccc}
\hline Parâmetros & \multicolumn{4}{c}{ Tratamentos } \\
\hline & $\mathrm{Hal}^{\mathrm{NN}} \mathrm{SR}$ & $\mathrm{Hal}^{\mathrm{NN}} \mathrm{CR}$ & $\mathrm{Hal}^{\mathrm{Nn}} \mathrm{SR}$ & $\mathrm{Hal}^{\mathrm{Nn}} \mathrm{CR}$ \\
Custo de ração R $\$ / \mathrm{kg}$ de peso vivo & $2,19 \mathrm{a}$ & $2,31 \mathrm{~b}$ & $2,23 \mathrm{a}$ & $2,38 \mathrm{c}$ \\
Índice de eficiência econômica & 100 & 0,95 & 0,98 & 0,92 \\
Índice de custo médio & 100 & 105,48 & 101,80 & 109,67 \\
\hline
\end{tabular}

Os resultados econômicos, medidos pelos índices de eficiência econômica e de custo, indicam que suínos homozigotos dominantes para o gene halotano $\left(\mathrm{Hal}^{\mathrm{NN}}\right)$ e os heterozigotos $\left(\mathrm{Hal}^{\mathrm{Nn}}\right)$, que não consumiram ractopamina apresentaram os melhores resultados $(\mathrm{P}<0,05)$, seguidos dos grupos homozigoto dominante com inclusão de 10 ppm de ractopamina e heterozigotos com inclusão de 10 ppm de ractopamina.

\section{Conclusões}

O desempenho e a qualidade da carcaça não são influenciados pela presença do gene halotano ou pela suplementação de ractopamina na dieta. 


\section{Agradecimentos}

Ao CNPq, pela concessão da bolsa de RecémDoutor à primeira autora e pela ajuda financeira concedida através da taxa de bancada.

À Empresa ELANCO do Brasil, pelo apoio financeiro para a execução deste experimento.

\section{Referências}

ANDERSON, D. B.; BOWERS, K. A.; IVERS D. J.; ZIMMERMANN, A. G. Environmental value of paylean in swine diets: nitrogen and phosporus excretion. In: INTERNATIONAL PIG VETERINARY SOCIETY CONGRESS, 17., 2002, Iowa. Proceedings... Iowa: IPVS, 2002. v. 2, p. 631.

ARMSTRONG, T. A.; KREMER, B. T.; SPIKE, T. E. Nutritional considerations for pigs fed ractopamine (PAYLEAN®). In: INTERNATIONAL PIG VETERINARY SOCIETY CONGRESS, 17., 2002, Iowa. Proceedings... Iowa: IPVS, 2002. v. 2, p. 630.

ASSOCIAÇÃO BRASILEIRA DE CRIADORES DE SUÍNOS - ABCS. Métodos brasileiro de classificação de carcaças. 2.ed. Rio Grande do Sul: Estrela, 1973.

BARBOSA, H. P.; FIALHO, E. T.; FERREIRA, A. S.; LIMA, G. J. M. M.; GOMESS, M. F. M. Triguilho para suínos nas fases inicial de crescimento, crescimento e terminação. Revista Brasileira de Zootecnia, Viçosa, v. 21, n. 1, p. 27-37, 1992.

BARK, L. J.; STAHLY, T. S.; CROMWELL, G. L. Influence of genetic capacity for lean tissue growth on responses of pigs to recombinant porcine somatotropin. Journal of Animal Science, Champaign, v. 68, n. 1, p. 212, 1989.

BELlAVER, C.; FIALHO, E. T.; PROTAS, J. F. S.; GOMES, M. F. M. Radícula de malte na alimentação de suínos em crescimento e terminação. Pesquisa Agropecuária Brasileira, Brasília, v. 20, n. 8, p. 969-974, 1985.

BRIDI, A. M.; NICOLAIEWSKY, S.; RUBENSAM, J. M.; BOTH, M. C.; LOBATO, J. F. P. Efeito do genótipo halotano e de diferentes sistemas de produção no desempenho produtivo e na qualidade da carcaça suína. Revista Brasileira de Zootecnia, Viçosa, v. 32, n. 4, p. 942-950, 2003.

CHANNON, H. A.; PAYNE, A. M.; WARNER, R. D. Halothane genotype, pre-slaughter handling and stunning method all influence pork quality. Meat Science, Barking, v. 56, n. 3, p. 291-299, 2000.
CRENSHAW, J. D.; SWANTEK, P. M.; MARCHELLO, M. J.; HARROLD, R. L.; ZIMPRICH, R. C.; OLSON, R. D. Effects of a phenethanolamine (ractopamine) on swine carcass composition. Journal of Animal Science, Champaign, v. 65, n. 2, p. 308, 1987.

CUARON, J. A.; MEJIA-GUADARRAMA, C. A. Ractopamine for restricted fed gilts: refeeding after a web withdrawal. In:INTERNATIONAL PIG VETERINARY SOCIETY CONGRESS, 17., 2002, Iowa. Proceedings... Iowa: IPVS, 2002. v. 1, p. 264.

DUGAN, M. E. R.; TONG, A. K. W.; CARLSON, J. P.; SCHRICKER, B. R.; AALHUS, J. L.; SCHAEFER, A. P.; SATHER, A. P.; MURRAY, A. C.; JONES, S. D. M. The effects of porcine somatotropin, gender and porcine stress syndrome on growth, carcass composition and pork quality. Canadian Journal of Animal Science, Ottawa, v. 72, n. 1, p. 233-240, 1997.

FISHER, P.; MELLETT, F. D.; HOFFMAN, L. C. Halothane genotype and pork quality. 1. Carcass and meat quality characteristics of three halothane genotypes. Meat Science, Barking, v. 54, n. 1, p. 97-105, 2000.

FUJII, J.; OTSU, K.; ZORZATO, F.; LEON, S.; KHANNA, V. K.; WEILER, J. E.; O'BRIEN, P. J.; MACLANNAN, D. H. Identification of a mutation in porcine ryanodine receptor associated with malignant hyperthermia. Science, Washington, v. 253, n. 2, p. 448$451,1991$.

GUIDONI, A. L. Melhoria de processos para a tipificação e valorização de carcaças suínas no Brasil. In: CONFERÊNCIA INTERNACIONAL VIRTUAL SOBRE QUALIDADE DE CARNE SUÍNA, 1., 2000, Concórdia: Brasil. Anais... Concórdia: EMBRAPACPSA, 2000. p. 221-234.

HAMILTON, D. N.; ELLIS, M.; MILLER, K. D.; McKEITH, F. K.; PARRETT, D. F. The effect of the halothane and rendement napole genes on carcass and meat quality characteristics of pigs. Journal of Animal Science, Champaign, v. 78, n. 11, p. 2862-2867, 2000.

JONES, S. D. M.; MURAY, A. C.; SATHER, A. P.; ROBERTSON, W. M. Body proportions and carcass composition of pigs with know genotypes for stress susceptibility fasted for different periods of time prior to slaughter. Canadian Journal of Animal Science, Ottawa, v. 68, n. 1, p. 139, 1988.

LEACH, L. M.; ELLIS, M.; SUTTON, D. S.; McKEITH, F. K.; WILSON, E. R. The growth performance, carcass characteristics, and meat quality of halothane carrier and negative pigs. Journal of Animal Science, Champaign, v. 74, n. 5, p. 934-943, 1996. 
MERSMANN, H. J. Species variations in mechanisms for modulation of growth by beta-agonist receptors. The Journal of Nutrition, Philadelphia, v. 125, p. 1777-1782, 1995.

MILlER, S. A.; DYKES, D. D.; POLESKY, H. F. A simple salting out procedure for extracting DNA from human necleated cells. Nucleic Acids Research, Oxford, v. 16, n. 4, p. 1215, 1988.

NATIONAL RESEARCH COUNCIL - NRC. Nutricional requirements of swine. 10.ed. Washington: National Academic of Science, 1998.

POLICARPIO, L. S.; CASTRO, J. L. The effects of ractopamine on production efficiencies and carcass lean gain. In: INTERNATIONAL PIG VETERINARY SOCIETY CONGRESS, 17., 2002, Iowa. Paylean Abstracts... Iowa: IPVS, 2002. p. 1-2.

SATHER, A. P.; MURRAY, A. C.; ZAWADSKI, S. M.; JOHNSON, P. The effect of the halothane genotype on pork production and meat quality of pigs reared under commercial conditions. Canadian Journal of Animal Science, Ottawa, v. 71, n. 4, p. 959-967, 1991.

SEE, M. T.; ARMSTRONG, T. A.; WELDON, W. C. Ractopamine (Paylean $\AA$ ) feeding program effects growth performance, feed cost and carcass value.In: INTERNATIONAL PIG VETERINARY SOCIETY CONGRESS, 17., 2002, Iowa. Proceedings... Iowa: USA, 2002. v. 1, p. 263.
STOLLER, G. M.; ZERBY, H. N.; MOELLER, S. J.; BAAS, T. J.; JOHNSON, C.; WATKINS, L. E. The effect of feeding ractopamine (paylean) on muscle quality and sensory characteristics in three diverse genetic lines of swine. Journal of Animal Science, Champaign, v. 81, n. 6, p. 1508-1516, 2003.

UNIVERSIDADE FEDERAL DE VIÇOSA. SAEG: Sistema de análises estatísticas e genéticas: manual do usuário. Versão 7.1. Viçosa: UFV, 1997.

VERNON, R. G. The growth and metabolism of adipocytes. In: BUTTERY, R. J.; LINDSAY, D. B.; HAYNES, N. B. (Ed.). Control and manipulation of animal growth. London: Butterworths, 1986. p. 77.

ZAGURY, F. T. R.; SILVEIRA, E. T. F.; VELOSO, J. A. F.; ANGERAMI, C. N.; SANTOS, C. G. L.; BRUNETTA, G. Effects of ractopamine (Paylean ${ }^{\circledR}$ ) on lean meat accretion and pork quality. In: INTERNATIONAL PIG VETERINARY SOCIETY CONGRESS, 17., 2002, Iowa. Proceedings... Iowa: IPVS, 2002. v. 2, p. 446.

WARRIS, P. D.; BROWN, S. N.; ROLPH, T. P.; KESTIN, S. C. Interactions between the beta-adrenergic agonist salbutamol and genotype on meat quality in pigs. Journal of Animal Science, Champaign, v. 68, n. 11, p. 3669-3676, 1990. 